\title{
A Real Time Algorithm to Monitor GNSS Positioning Services
}

\author{
John Kwamena Amos ${ }^{1}$, Perry Addison ${ }^{2}$ \\ ${ }^{1,2}$ Civil Engineering Department, Takoradi Polytechnic, Ghana
}

\begin{abstract}
The aim of permanent networks is to provide network correction information to RTK or Static rover users to derive their positions with a higher accuracy. The proposed algorithm was tested on a network of permanent networks belonging to Leica SmartNetItalPoS. The "leave one" out statistical method was applied. Two controls were implemented in the process. Control 1 (C1) in which the excluded station is estimated in real time by using the surrounding stations and the network products and in control 2 (C2), network products are used to simulate data of a "virtual user" in the position of the excluded station. Several experiments were performed to test the algorithm using different network configurations and imposed errors in height to understand the effectiveness of the controls. For imposed errors in the height, $\mathrm{Cl}$ provided exactly the expected results, with a bias in the estimates almost equal to the introduced error in the reference station and the results variations depended on network configuration. C2 failures increase significantly with the error increase, but the errors of fixed estimates are not linearly dependent on it. The study recommends further experiments in other reference frames and a future improvement on the proposed algorithm.
\end{abstract}

Keywords: Permanent network (PN), Quality control (QC), Virtual user, Global Positioning System (GPS), International Terrestrial Reference Frame (ITRF),European Terrestrial Reference System (ETRF)

\section{Introduction}

In recent times the use of networks of multiple GPS reference stations for generating corrections instead of standard single baseline approaches has emerged with great promise for use in real-time environments and has been receiving a significant amount of attention from people working on geodesy, surveying, cartography and mapping (Euler et al., 2001; Wubbena, 2001; Chen et al., 2003). This is because it provides a significant capability of reducing time and costs for survey campaigns. Also there is an increase in reliability and availability of the service. Another quite important aspect of the network approach is that it allows us to accurately model the distance dependent or spatially correlated errors, such as ionospheric, troposphere and satellite orbit effects (Biagi and Sanso, 2007).

The Leica Geosystems Italia network named SmartNetItalPoS was the first network of permanent GNSS stations with national coverage in Italy. It represents an example of a commercial GNSS network for positioning services. Leica SmartNetItalPoS is made up of over one hundred high quality GNSS reference stations.

LEICA GNSS Spiders a suite of software for the management, operation and continuous monitoring of SmartNetItalPoS networks of stations. LEICA GNSS Spider "SpiderNET" is a module within GNSS Spider for real-time network analysis and error modeling. SmartNetItalPoS provides real time network products for real time processing services and distributes data and services for the post processing applications. An essential point is the quality check on the stations coordinates and of the network products it offers to its clients. This means it is important that some quality checks and accuracies index should be made available to the user.

\section{Methodology / Proposed Process}

The algorithm presented here has been tested on a network of permanent networks belonging to Leica SmartNetItalPoS. In total a network of 15 stations located in the center of Italy were used for the experiment. Before starting the network, a sub network was created and one station was excluded from the network. Real time computations were started and the ambiguities of the network were resolved to a common ambiguity level. The computation of the Real Time products started.

Two controls were implemented in the process. First control (C1) in which the excluded station was estimated in real time by using the surrounding stations and the network products. In the second control (C2), network products were used to simulate data of a virtual user in the position of the excluded station. The baseline between each excluded station and the corresponding simulated virtual user was estimated in real time.

The differences between the real time estimates of the controls and the expected results (Quality control 1 and 2 i.e. QC1 and QC2) were compared to lower and upper threshold LT and UT respectively, this is level 1 as shown in the flux flow (figure 1). Stations that passed both the LT of $\mathrm{C} 1$ and $\mathrm{C} 2$ were included in the network. For stations that exceeded LT of $\mathrm{C} 1$ and $\mathrm{C} 2$ but not UT a warning message was sent to the administrator.

The excluded stations that had not passed the upper thresholds of the Level 1 quality checks were passed to Level 2 and the two controls are again performed. The new errors were again compared with the relevant upper thresholds. All the differences that were smaller than the threshold were reported to the network administrator and the process passed to step 'Reset'. The stations that did not pass the quality controls were put in quarantine and temporally excluded from the network. 


\section{International Journal of Science and Research (IJSR) \\ ISSN (Online): 2319-7064}

Index Copernicus Value (2013): 6.14 | Impact Factor (2015): 6.391

\subsection{Set up of the experiments}

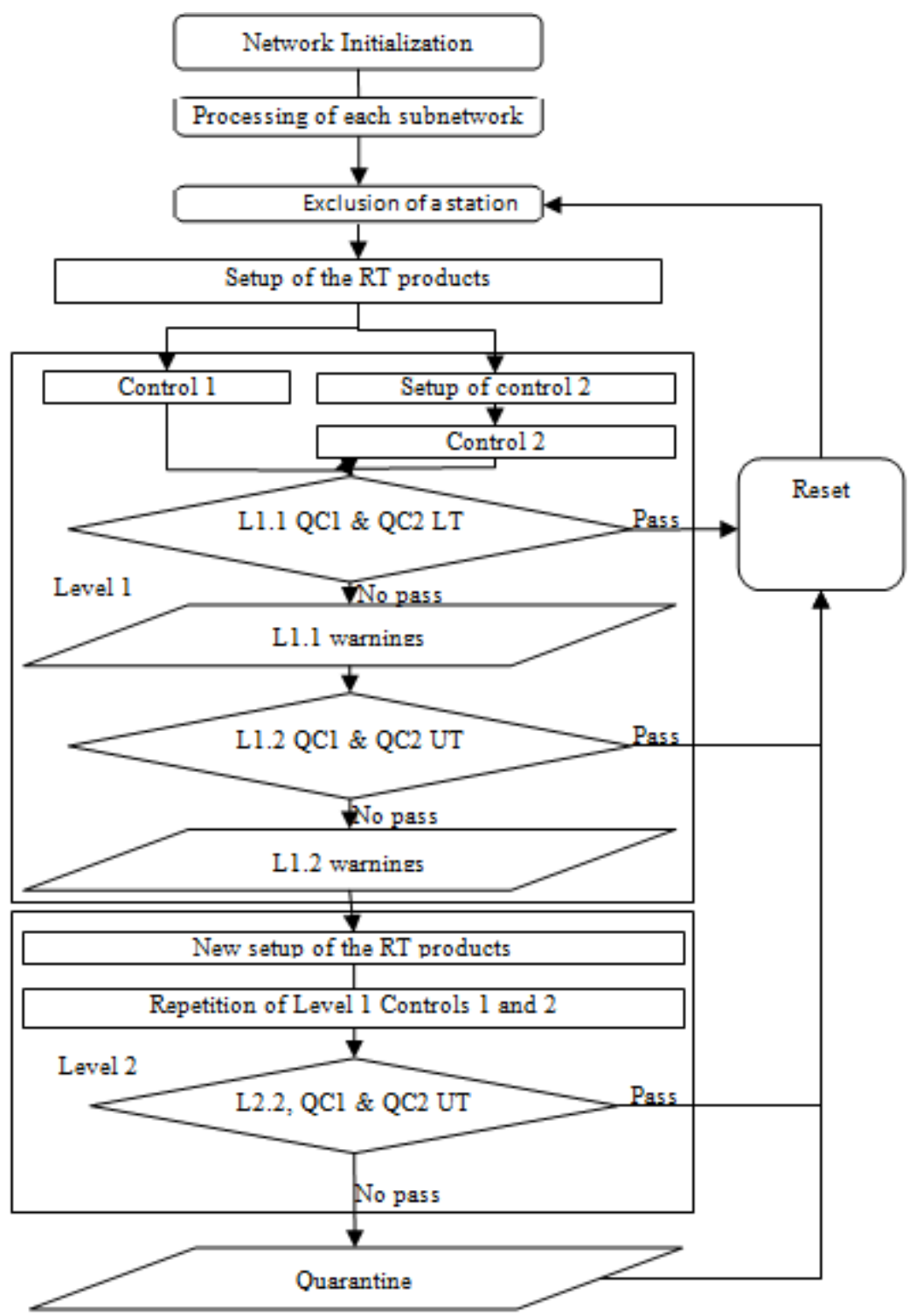

Figure 1: Flux diagram

A network of 15 stations located in the center of Italy (figure2) was used to perform the experiments. All the stations belong to ItalPos network. The mean distance between the stations was about $80 \mathrm{~km}$. The software used to manage the stations was Leica GNSS Spider version 4.0.1. All the experiments were performed with a general procedure. Firstly, one station was excluded from the network processing in order to simulate on it the proposed real time quality checks. Errors were introduced in the apriori coordinates of one other station, in order to simulate some criticality which propagation on $\mathrm{C} 1$ and $\mathrm{C} 2$ results were investigated. Then the network is started. Two thresholds in time were imposed to define both a successful or not successful network fixing and a fixed positioning of the excluded station. This was needed especially for the experiments in which big errors were introduced in the coordinates. 10 minutes of maximum time for network fixing, and 5 minutes of maximum time for a fixed positioning of the excluded station. Figure 2 shows the cluster of permanent stations adopted for the experiments. A master station was necessary to define the cluster: MORO was chosen because of its barycentric position. 


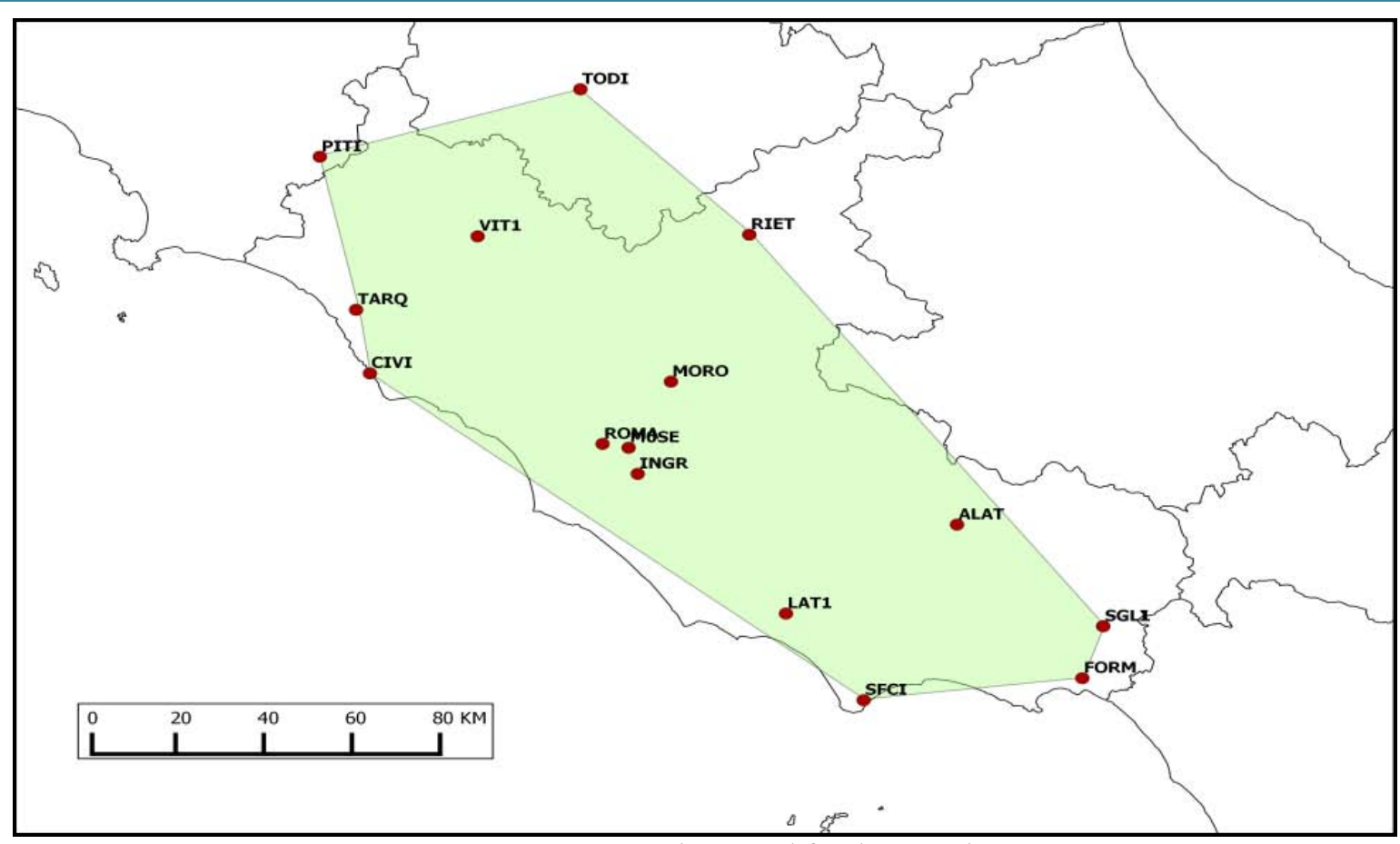

Figure 2: Permanent stations used for the experiments

\section{Experiments, Results and Analysis}

An experiment was set up to test the proposed algorithm. Several tests were performed, that were classified based on different criteria:

\subsection{Preliminary test: comparison between ITRF and ETRF}

Preliminary tests: Estimation of ROMA with respect to M0SE in ITRF vs. ETRF.
To understand the influence of the reference frame, both Control 1 and Control 2 were performed to estimate only ROMA with respect to MOSE by setting the network coordinates once in IGS08 and once in ETRF00 reference frame. The network was initialized 15 times: for each initialization, one estimate of ROMA (Control 1) and Virtual User in Roma (Control 2) were computed by averaging the first ten fixed solutions. A total of 15 experiments were conducted and their average calculated.

Table 1: Estimation errors of ROMA with respect to MOSE as nearest station and of ROMA Virtual User with respect to ROMA in IGS08 and ETRF00. E: mean, $\delta$ : standard deviation, M: maximum absolute value. Values in mm

\begin{tabular}{|c|c|c|c|c|c|c|c|c|c|c|c|c|c|}
\hline & \multicolumn{9}{|c|}{ ITRS } & \multicolumn{5}{|c|}{ ETRF00 } \\
\hline & \multicolumn{2}{|c|}{ C1 (ROMA) } & \multicolumn{2}{c|}{ C2 (Virtual User) } & \multicolumn{2}{c|}{ C1 (ROMA) } \\
\hline Exp \# & North & East & Up & North & East & Up & North & East & Up & North & East & Up \\
\hline E & 9 & 8 & 18 & -8 & -10 & -15 & 15 & 6 & 26 & -11 & -13 & -29 \\
\hline$\Sigma$ & 6 & 6 & 9 & 6 & 5 & 10 & 5 & 9 & 11 & 6 & 4 & 13 \\
\hline M & 21 & 18 & 39 & 17 & 19 & 37 & 22 & 24 & 51 & 18 & 22 & 57 \\
\hline
\end{tabular}

One height bias was clear in ETRF with opposite sign in $\mathrm{C} 1$ and $\mathrm{C} 2$. However, the accuracy of the result was consistent with the typical accuracy of real time positioning.

\subsection{Tests of sensitivity in ITRF}

In each experiment, a station was excluded from the network. Increasing errors from $0 \mathrm{~cm}$ to $20 \mathrm{~cm}$, by steps of 5 $\mathrm{cm}$, were introduced in the apriori height (up or $\mathrm{z}$ ) coordinate of the near or far (dense or sparse network configuration) station. For each error level, ten network initializations were done. For each initialization, one estimate of both the excluded station (Control 1) and zero baseline between the excluded station and the Virtual User (Control 2) were performed. The results were obtained by averaging the first ten fixed solutions and compared with the known coordinates of the station. A total of 10 experiments were conducted and their average calculated.
3.2.1 Exp. $\mathrm{N}^{\circ} 1$ - ROMA estimation with respect to MORO. INGR and MOSE excluded from the network calculus; growing errors imposed in MORO height: (no errors, $5 \mathrm{~cm}$ error, $10 \mathrm{~cm}$ error, $15 \mathrm{~cm}$ error and $20 \mathrm{~cm}$ error)

Table 2: Estimation errors of ROMA with respect to MORO as near station without error and of ROMA Virtual User with respect to ROMA in IGS08. E: mean, $\sigma:$ standard deviation, M: maximum absolute value. Values are in $\mathrm{mm}$

\begin{tabular}{|l|l|l|l|l|l|l|}
\hline & \multicolumn{3}{|l|}{ C1 (ROMA) } & \multicolumn{3}{c|}{ C2 (Virtual User) } \\
\hline Exp \# & North & East & Up & North & East & Up \\
\hline E & $\mathbf{- 1}$ & $\mathbf{1 0}$ & $\mathbf{- 7}$ & $\mathbf{- 1}$ & $\mathbf{- 1 8}$ & $\mathbf{- 2 2}$ \\
\hline$\Sigma$ & $\mathbf{8}$ & $\mathbf{9}$ & $\mathbf{1 2}$ & $\mathbf{1 4}$ & $\mathbf{2 2}$ & $\mathbf{4 4}$ \\
\hline M & $\mathbf{1 5}$ & $\mathbf{2 5}$ & $\mathbf{2 3}$ & $\mathbf{3 5}$ & $\mathbf{4 4}$ & $\mathbf{1 1 9}$ \\
\hline
\end{tabular}




\section{International Journal of Science and Research (IJSR) \\ ISSN (Online): 2319-7064 \\ Index Copernicus Value (2013): 6.14 | Impact Factor (2015): 6.391}

Table 3: Estimation errors of ROMA with respect to MORO as near station with $5 \mathrm{~cm}$ error in MORO height and of ROMA Virtual User with respect to ROMA in IGS08. E: mean, $\sigma$ standard deviation, M: maximum absolute value.

Values are in $\mathrm{mm}$

\begin{tabular}{|l|l|l|l|l|l|l|}
\hline & \multicolumn{3}{|l|}{ C1 (ROMA) } & \multicolumn{3}{c|}{ C2 (Virtual User) } \\
\hline Exp \# & North & East & Up & North & East & Up \\
\hline E & $\mathbf{- 8}$ & $\mathbf{3}$ & $\mathbf{4 8}$ & $\mathbf{7}$ & $\mathbf{- 9}$ & $\mathbf{- 3 8}$ \\
\hline$\Sigma$ & $\mathbf{1 0}$ & $\mathbf{7}$ & $\mathbf{1 1}$ & $\mathbf{6}$ & $\mathbf{1 0}$ & $\mathbf{3 1}$ \\
\hline M & $\mathbf{2 8}$ & $\mathbf{1 2}$ & $\mathbf{6 1}$ & $\mathbf{2 1}$ & $\mathbf{2 6}$ & $\mathbf{5 9}$ \\
\hline
\end{tabular}

Table 4: Estimation errors of ROMA with respect to MORO as near station with $10 \mathrm{~cm}$ error in MORO height and of ROMA Virtual User with respect to ROMA in IGS08. E: mean, $\sigma$ standard deviation, M: maximum absolute value. Values are in $\mathrm{mm}$. [xx represents a fixing failure in the solutions or in the network calculus]

\begin{tabular}{|c|c|c|c|c|c|c|}
\hline & \multicolumn{3}{|c|}{ C1 (ROMA) } & \multicolumn{3}{c|}{ C2 (Virtual User) } \\
\hline Exp \# & North & East & Up & North & East & Up \\
\hline 1 & -7 & -1 & 52 & 24 & 5 & -49 \\
\hline 2 & -8 & 16 & 79 & 19 & -31 & -39 \\
\hline 3 & -12 & -10 & 83 & -8 & -14 & -33 \\
\hline 4 & -3 & 12 & 83 & $\mathbf{x x}$ & $\mathbf{x x}$ & $\mathbf{X x}$ \\
\hline 5 & -22 & 20 & 54 & 28 & -10 & 41 \\
\hline 6 & 13 & 3 & 58 & 31 & -11 & -77 \\
\hline 7 & 2 & 7 & 34 & $\mathbf{x x}$ & $\mathbf{x x}$ & $\mathbf{X x}$ \\
\hline 8 & 2 & 6 & 93 & 44 & 29 & 80 \\
\hline 9 & 2 & -7 & 107 & 8 & -4 & -70 \\
\hline 10 & 6 & -11 & 112 & $\mathbf{x x}$ & $\mathbf{x x}$ & $\mathbf{X x}$ \\
\hline E & $\mathbf{- 3}$ & $\mathbf{3}$ & $\mathbf{7 6}$ & $\mathbf{1 9}$ & $\mathbf{- 1 2}$ & $\mathbf{- 3 1}$ \\
\hline$\Sigma$ & $\mathbf{1 0}$ & $\mathbf{1 1}$ & $\mathbf{2 5}$ & $\mathbf{1 6}$ & $\mathbf{1 3}$ & $\mathbf{4 4}$ \\
\hline $\mathrm{M}$ & $\mathbf{2 2}$ & $\mathbf{2 0}$ & $\mathbf{1 1 2}$ & $\mathbf{4 4}$ & $\mathbf{3 1}$ & $\mathbf{8 0}$ \\
\hline
\end{tabular}

Table 5: Estimation errors of ROMA with respect to MORO as near station with $20 \mathrm{~cm}$ error in MORO height and of ROMA Virtual User with respect to ROMA in IGS08. E: mean, $\sigma$ : standard deviation, M: maximum absolute value. Values are in $\mathrm{mm}$. [xx represents a fixing failure in the solutions or in the network calculus]

\begin{tabular}{|c|c|c|c|c|c|c|}
\hline & \multicolumn{3}{|c|}{ C1 (ROMA) } & \multicolumn{3}{c|}{ C2 (Virtual User) } \\
\hline Exp \# & North & East & Up & North & East & Up \\
\hline 1 & -8 & -1 & 219 & $\mathbf{x x}$ & $\mathbf{x x}$ & $\mathbf{x x}$ \\
\hline 2 & -10 & 1 & 228 & $\mathbf{x x}$ & $\mathbf{x x}$ & $\mathbf{x x}$ \\
\hline 3 & 5 & -3 & 259 & $\mathbf{x x}$ & $\mathbf{x x}$ & $\mathbf{x x}$ \\
\hline 4 & -11 & -6 & 209 & 47 & 21 & 36 \\
\hline 5 & -9 & 11 & 220 & -10 & -8 & -18 \\
\hline 6 & 14 & 2 & 237 & $\mathbf{x x}$ & $\mathbf{x x}$ & $\mathbf{x x}$ \\
\hline 7 & 18 & -4 & 224 & -38 & 49 & 24 \\
\hline 8 & 6 & 8 & 189 & 6 & 27 & 147 \\
\hline 9 & -17 & 15 & 188 & 9 & -14 & 40 \\
\hline 10 & -1 & 25 & 212 & $\mathbf{x x}$ & $\mathbf{x x}$ & $\mathbf{x x}$ \\
\hline E & $-\mathbf{1}$ & $\mathbf{5}$ & $\mathbf{2 1 9}$ & $\mathbf{1 9}$ & $\mathbf{6}$ & $\mathbf{9}$ \\
\hline$\Sigma$ & $\mathbf{1 2}$ & $\mathbf{1 0}$ & $\mathbf{2 1}$ & $\mathbf{3 1}$ & $\mathbf{2 6}$ & $\mathbf{6 1}$ \\
\hline $\mathrm{M}$ & $\mathbf{1 8}$ & $\mathbf{2 5}$ & $\mathbf{2 5 9}$ & $\mathbf{4 7}$ & $\mathbf{2 7}$ & $\mathbf{1 4 7}$ \\
\hline
\end{tabular}

The mean estimation errors of ROMA (C1) showed results almost perfectly testify the introduced error in MORO. The results dispersions were similar to those obtained without errors. C2 results were in some way more chaotic. No clear linear dependence between MORO error and mean estimation error could be seen. Moreover to a MORO error increase an increase of the estimations standard deviation corresponded. Furthermore, for MORO errors bigger than
$10 \mathrm{~cm}$, the success percentages decreased. This was expected, indeed:

- C1 was substantially baseline estimation from MORO to ROMA. ROMA bias was directly affected by errors in the problems in one particular station.

- C2 was a test on network product, whose accuracy was affected in a complicated and nonlinear dependence form

3.2.2 Exp. $\mathrm{N}^{\circ} 2$ - ROMA estimation with respect to MORO. INGR and MOSE included in the network calculus; growing errors imposed in MORO height :( no errors, $5 \mathrm{~cm}$ error, $10 \mathrm{~cm}$ error, $15 \mathrm{~cm}$ error and $20 \mathrm{~cm}$ error)

Table 6: Estimation errors of ROMA with respect to MORO as near station with $0 \mathrm{~cm}$ error in MORO height coordinate and of ROMA Virtual User with respect to ROMA in IGS08. E: mean, $\sigma$ standard deviation, $\mathrm{M}$ : maximum absolute value. Values are in $\mathrm{mm}$

\begin{tabular}{|c|c|c|c|c|c|c|}
\hline & \multicolumn{3}{|c|}{ C1 (ROMA) } & \multicolumn{3}{c|}{ C2 (Virtual User) } \\
\hline Exp \# & North & East & Up & North & East & Up \\
\hline E & $\mathbf{2}$ & $\mathbf{3}$ & $\mathbf{- 1 8}$ & $\mathbf{- 6}$ & $\mathbf{- 1 6}$ & $\mathbf{- 3}$ \\
\hline$\Sigma$ & $\mathbf{8}$ & $\mathbf{1 1}$ & $\mathbf{2 2}$ & $\mathbf{8}$ & $\mathbf{8}$ & $\mathbf{2 2}$ \\
\hline M & $\mathbf{1 6}$ & $\mathbf{1 9}$ & $\mathbf{6 1}$ & $\mathbf{1 7}$ & $\mathbf{3 0}$ & $\mathbf{4 3}$ \\
\hline
\end{tabular}

Table 7: Estimation errors of ROMA with respect to MORO as near station with $5 \mathrm{~cm}$ error in MORO height coordinate and of ROMA Virtual User with respect to ROMA in IGS08. E: mean, $\sigma$ standard deviation, $M$ : maximum absolute value. Values are in $\mathrm{mm}$.

\begin{tabular}{|c|c|c|c|c|c|c|}
\hline & \multicolumn{3}{|c|}{ C1 (ROMA) } & \multicolumn{3}{c|}{ C2 (Virtual User) } \\
\hline Exp \# & North & East & Up & North & East & Up \\
\hline E & $\mathbf{1}$ & $\mathbf{4}$ & $\mathbf{3 0}$ & $\mathbf{- 6}$ & $\mathbf{- 1 1}$ & $\mathbf{- 1 7}$ \\
\hline$\Sigma$ & $\mathbf{1 3}$ & $\mathbf{7}$ & $\mathbf{1 5}$ & $\mathbf{9}$ & $\mathbf{4}$ & $\mathbf{1 4}$ \\
\hline $\mathrm{M}$ & $\mathbf{2 6}$ & $\mathbf{1 3}$ & $\mathbf{5 8}$ & $\mathbf{1 6}$ & $\mathbf{1 6}$ & $\mathbf{3 6}$ \\
\hline
\end{tabular}

Table 8: Estimation errors of ROMA with respect to MORO as near station with $10 \mathrm{~cm}$ error in MORO height coordinate and of ROMA Virtual User with respect to ROMA in IGS08. E: mean, $\sigma$ standard deviation, M: maximum absolute value. Values are in $\mathrm{mm}$

\begin{tabular}{|l|l|l|l|l|l|l|}
\hline & \multicolumn{3}{|l|}{ C1 (ROMA) } & \multicolumn{3}{c|}{ C2 (Virtual User) } \\
\hline Exp \# & North & East & Up & North & East & Up \\
\hline E & $\mathbf{3}$ & $\mathbf{2}$ & $\mathbf{7 7}$ & $\mathbf{- 7}$ & $\mathbf{- 2}$ & $\mathbf{2 5}$ \\
\hline$\Sigma$ & $\mathbf{1 3}$ & $\mathbf{1 4}$ & $\mathbf{2 4}$ & $\mathbf{6}$ & $\mathbf{1 4}$ & $\mathbf{2 3}$ \\
\hline M & $\mathbf{2 6}$ & $\mathbf{2 7}$ & $\mathbf{1 1 0}$ & $\mathbf{1 4}$ & $\mathbf{2 7}$ & $\mathbf{5 2}$ \\
\hline
\end{tabular}




\section{International Journal of Science and Research (IJSR) ISSN (Online): 2319-7064 \\ Index Copernicus Value (2013): 6.14 | Impact Factor (2015): 6.391}

Table 9: Estimation errors of ROMA with respect to MORO as near station with $20 \mathrm{~cm}$ error in height coordinate and of ROMA Virtual User with respect to ROMA in IGS08. E: mean, $\sigma$ standard deviation, M: maximum absolute value. Values are in $\mathrm{mm}$. [xx represents a fixing failure in the solutions or in the network calculus]

\begin{tabular}{|c|c|c|c|c|c|c|}
\hline & \multicolumn{3}{|c|}{ C1 (ROMA) } & \multicolumn{3}{c|}{ C2 (Virtual User) } \\
\hline Exp \# & North & East & Up & North & East & Up \\
\hline 1 & -20 & 6 & 142 & -14 & -11 & 24 \\
\hline 2 & -1 & 5 & 153 & -18 & -3 & 21 \\
\hline 3 & 7 & -5 & 115 & -12 & 1 & 28 \\
\hline 4 & 1 & 10 & 114 & -2 & -9 & 19 \\
\hline 5 & 2 & 5 & 136 & 1 & -5 & 54 \\
\hline 6 & 0 & 4 & 113 & -10 & -20 & 14 \\
\hline 7 & 4 & -10 & 82 & -14 & -8 & 16 \\
\hline 8 & 7 & -5 & 66 & -20 & -2 & 35 \\
\hline 9 & 5 & 0 & 122 & $\mathbf{x x}$ & $\mathbf{x x}$ & $\mathbf{X x}$ \\
\hline 10 & -1 & 20 & 71 & -4 & -7 & -13 \\
\hline $\mathrm{E}$ & $\mathbf{0}$ & $\mathbf{3}$ & $\mathbf{1 1 2}$ & $\mathbf{- 9}$ & $\mathbf{- 6}$ & $\mathbf{2 2}$ \\
\hline$\Sigma$ & $\mathbf{8}$ & $\mathbf{9}$ & $\mathbf{3 0}$ & $\mathbf{7}$ & $\mathbf{6}$ & $\mathbf{1 8}$ \\
\hline $\mathrm{M}$ & $\mathbf{2 0}$ & $\mathbf{2 0}$ & $\mathbf{1 5 3}$ & $\mathbf{2 0}$ & $\mathbf{2 0}$ & $\mathbf{5 4}$ \\
\hline
\end{tabular}

C1 results confirmed the previous considerations. In presence of a denser network, C2 was no significantly affected by an error in a far station.

\subsection{3: Exp. $\mathrm{N}^{\circ} 3$ - ROMA estimation with respect to MOSE} with imposed errors in MOSE height :( $5 \mathrm{~cm}$ error, $10 \mathrm{~cm}$ error, $15 \mathrm{~cm}$ error, $20 \mathrm{~cm}$ error)

Table 10: Estimation errors of ROMA with respect to MOSE as near station with $0 \mathrm{~cm}$ error in MOSE height and of ROMA Virtual User with respect to ROMA in IGS08. E: mean, $\sigma$ standard deviation, $\mathrm{M}$ : maximum absolute value. Values are in $\mathrm{mm}$

\begin{tabular}{|c|c|c|c|c|c|c|}
\hline & \multicolumn{3}{|c|}{ C1 (ROMA) } & \multicolumn{3}{c|}{ C2 (Virtual User) } \\
\hline Exp \# & North & East & Up & North & East & Up \\
\hline E & $\mathbf{5}$ & $\mathbf{1 1}$ & $\mathbf{1 4}$ & $\mathbf{- 1}$ & $\mathbf{0}$ & $\mathbf{- 1}$ \\
\hline$\Sigma$ & $\mathbf{6}$ & $\mathbf{4}$ & $\mathbf{6}$ & $\mathbf{1}$ & $\mathbf{1}$ & $\mathbf{4}$ \\
\hline M & $\mathbf{1 2}$ & $\mathbf{1 6}$ & $\mathbf{2 2}$ & $\mathbf{2}$ & $\mathbf{2}$ & $\mathbf{6}$ \\
\hline
\end{tabular}

Table 11: Estimation errors of ROMA with respect to MOSE as near station with $5 \mathrm{~cm}$ error in MOSE height and of ROMA Virtual User with respect to ROMA in IGS08. E: mean, $\sigma$ standard deviation, $\mathrm{M}$ : maximum absolute value.

Values are in $\mathrm{mm}$

\begin{tabular}{|c|c|c|c|c|c|c|}
\hline & \multicolumn{3}{|c|}{ C1 (ROMA) } & \multicolumn{3}{c|}{ C2 (Virtual User) } \\
\hline Exp \# & North & East & Up & North & East & Up \\
\hline E & $\mathbf{1 3}$ & $\mathbf{4}$ & $\mathbf{5 5}$ & $\mathbf{- 2}$ & $\mathbf{- 7}$ & $\mathbf{- 4 6}$ \\
\hline$\Sigma$ & $\mathbf{7}$ & $\mathbf{4}$ & $\mathbf{1 4}$ & $\mathbf{1 2}$ & $\mathbf{7}$ & $\mathbf{2 3}$ \\
\hline M & $\mathbf{2 7}$ & $\mathbf{9}$ & $\mathbf{7 8}$ & $\mathbf{2 5}$ & $\mathbf{2 1}$ & $\mathbf{8 2}$ \\
\hline
\end{tabular}

Table 12: Estimation errors of ROMA with respect to MOSE as near station with $10 \mathrm{~cm}$ error in M0SE height and of ROMA Virtual User with respect to ROMA in IGS08. E: mean, $\sigma$ standard deviation, $\mathrm{M}$ : maximum absolute value.

$$
\text { Values are in } \mathrm{mm}
$$

\begin{tabular}{|c|c|c|c|c|c|c|}
\hline & \multicolumn{3}{|c|}{ C1 (ROMA) } & \multicolumn{3}{c|}{ C2 (Virtual User) } \\
\hline Exp \# & North & East & Up & North & East & Up \\
\hline E & $\mathbf{1 3}$ & $\mathbf{1}$ & $\mathbf{1 0 4}$ & $\mathbf{- 1 0}$ & $\mathbf{- 9}$ & $\mathbf{- 5 0}$ \\
\hline$\Sigma$ & $\mathbf{7}$ & $\mathbf{2}$ & $\mathbf{9}$ & $\mathbf{9}$ & $\mathbf{4}$ & $\mathbf{3 1}$ \\
\hline M & $\mathbf{2 1}$ & $\mathbf{4}$ & $\mathbf{1 0 9}$ & $\mathbf{2 4}$ & $\mathbf{1 4}$ & $\mathbf{9 2}$ \\
\hline
\end{tabular}

Table 13: Estimation errors of ROMA with respect to M0SE as near station with $20 \mathrm{~cm}$ error in M0SE height and of ROMA Virtual User with respect to ROMA in IGS08. E: mean, $\sigma$ standard deviation, $M$ : maximum absolute value.

Values are in $\mathrm{mm}$. [xx represents a fixing failure in the solutions or in the network calculus]

\begin{tabular}{|c|c|c|c|c|c|c|}
\hline & \multicolumn{3}{|c|}{ C1 (ROMA) } & \multicolumn{3}{c|}{ C2 (Virtual User) } \\
\hline Exp \# & North & East & Up & North & East & Up \\
\hline 1 & 7 & 12 & 204 & -14 & -14 & -259 \\
\hline 2 & 13 & 0 & 229 & -10 & -10 & -291 \\
\hline 3 & 4 & 3 & 215 & 0 & -14 & -269 \\
\hline 4 & 7 & 6 & 217 & $\mathbf{x x}$ & $\mathbf{x x}$ & $\mathbf{X x}$ \\
\hline 5 & 7 & 9 & 203 & $\mathbf{x x}$ & $\mathbf{x x}$ & $\mathbf{X x}$ \\
\hline 6 & 14 & 11 & 207 & $\mathbf{x x}$ & $\mathbf{x x}$ & $\mathbf{X x}$ \\
\hline 7 & 14 & 7 & 210 & 1 & -20 & -320 \\
\hline 8 & 7 & -1 & 220 & $\mathbf{x x}$ & $\mathbf{x x}$ & $\mathbf{X x}$ \\
\hline 9 & -3 & 0 & 252 & $\mathbf{x x}$ & $\mathbf{x x}$ & $\mathbf{X x}$ \\
\hline 10 & 8 & 2 & 218 & -37 & -4 & -256 \\
\hline E & $\mathbf{8}$ & $\mathbf{5}$ & $\mathbf{2 1 8}$ & $\mathbf{- 1 2}$ & $\mathbf{- 1 2}$ & $\mathbf{- 2 7 9}$ \\
\hline$\Sigma$ & $\mathbf{5}$ & $\mathbf{5}$ & $\mathbf{1 5}$ & $\mathbf{1 5}$ & $\mathbf{6}$ & $\mathbf{2 7}$ \\
\hline M & $\mathbf{1 4}$ & $\mathbf{1 2}$ & $\mathbf{2 5 2}$ & $\mathbf{3 7}$ & $\mathbf{2 0}$ & $\mathbf{3 2 0}$ \\
\hline
\end{tabular}

In this case, $\mathrm{C} 1$ provide exactly the expected results, with a bias in the estimates almost equal to the introduced error in the reference station. As in experiment 1, C2 failures increased significantly with the error increase, but the errors of fixed estimates were not linearly dependent on it.

3.2.4: Exp. $\mathrm{N}^{\circ} 4$ - ROMA estimation with respect to MOSE, with imposed errors in MORO height: $(5 \mathrm{~cm}$ error, $10 \mathrm{~cm}$ error, $15 \mathrm{~cm}$ error, $20 \mathrm{~cm}$ error)

Table 14: Estimation errors of ROMA with respect to MOSE as near station with $5 \mathrm{~cm}$ error in MORO height and of ROMA Virtual User with respect to ROMA in IGS08. E: mean, $\sigma$ standard deviation, M: maximum absolute value.

Values are in $\mathrm{mm}$

\begin{tabular}{|c|c|c|c|c|c|c|}
\hline & \multicolumn{3}{|c|}{ C1 (ROMA) } & \multicolumn{3}{c|}{ C2 (Virtual User) } \\
\hline Exp \# & North & East & Up & North & East & Up \\
\hline E & 9 & 9 & 12 & -2 & -12 & -4 \\
\hline$\Sigma$ & 4 & 4 & 10 & 4 & 5 & 10 \\
\hline M & 17 & 14 & 28 & 10 & 20 & 19 \\
\hline
\end{tabular}

Table 15: Estimation errors of ROMA with respect to MOSE as near station with $10 \mathrm{~cm}$ error in MORO height and of ROMA Virtual User with respect to ROMA in IGS08. E: mean, $\sigma$ standard deviation, $M$ : maximum absolute value.

Values are in $\mathrm{mm}$

\begin{tabular}{|l|l|l|l|l|l|l|}
\hline & \multicolumn{3}{|l|}{ C1 (ROMA) } & \multicolumn{3}{c|}{ C2 (Virtual User) } \\
\hline Exp \# & North & East & Up & North & East & Up \\
\hline E & 16 & 20 & 18 & -3 & -19 & -9 \\
\hline$\Sigma$ & 5 & 4 & 11 & 8 & 3 & 11 \\
\hline M & 23 & 29 & 29 & 14 & 23 & 30 \\
\hline
\end{tabular}

Table 16: Estimation errors of ROMA with respect to MOSE as near station with $20 \mathrm{~cm}$ error in MORO height and of ROMA Virtual User with respect to ROMA in IGS08. E: mean, $\sigma$ standard deviation, $M$ : maximum absolute value.

Values are in $\mathrm{mm}$

\begin{tabular}{|c|c|c|c|c|c|c|}
\hline & \multicolumn{3}{|c|}{ C1 (ROMA) } & \multicolumn{3}{c|}{ C2 (Virtual User) } \\
\hline Exp \# & North & East & Up & North & East & Up \\
\hline E & 10 & 8 & 20 & -8 & -9 & -24 \\
\hline$\Sigma$ & 9 & 9 & 20 & 7 & 5 & 16 \\
\hline M & 25 & 20 & 46 & 17 & 14 & 46 \\
\hline
\end{tabular}




\section{International Journal of Science and Research (IJSR) \\ ISSN (Online): 2319-7064 \\ Index Copernicus Value (2013): 6.14 | Impact Factor (2015): 6.391}

C1 results did not depend on the error. This was expected, because in this case, errors were not in the reference station for the baseline estimation. Also, $\mathrm{C} 1$ results seemed not affected by the introduced error in MORO and this was not exactly expected. More investigations in the future will be needed.

\section{Conclusion}

With the advent of GPS permanent network, that is the use of multiple reference stations in a network for providing positioning services, it is now possible for the network to better model and estimate the errors and provide network correction information in real time to rover users so that they may obtain positions with a higher accuracy. There is therefore a need for a quality check on the data that are sent from the network to the receiver.

This paper introduced an algorithm for the quality check on a network of permanent stations. The proposed process provided a cyclic quality control of the stations data and a continuous check of the network products. It was based on an empirical application of the "Leave One Out" statistic principle.

Having tested the proposed algorithm with experiments in ITRF, the overall results obtained for experiments without errors imposed had accuracies which were consistent with the typical accuracy of real time positioning for both quality checks.

For the experiments with imposed errors in the height, in the case of quality check 1 (C1), it provided exactly the expected results, with a bias in the estimates almost equal to the introduced error in the reference station depending on the station which was used as near and station that contained the error. It also depended on the network configuration (dense or sparse network). Tables 2 to 16 show the results.

It was also realized that $\mathrm{C} 2$ failures increased significantly with the error increase, but the errors of fixed estimates were not linearly dependent on it.

We recommend that further experiments should be carried out to better understand the network behavior when computations are performed in other reference system and also when errors are introduced in the planimetric coordinates. This proposed algorithm can be improved in the near future.

\section{References}

[1] Alves P, Kotthoff H, Geisler I., Zelzer O., Euler H.J., Rover Processing with Network RTK and Quality Indicators. ION NTM, 2006.

[2] Biagi L., I Fondamentali del GPS, Geomatics Workbooks Vol. 8, 236 pp, 2009

[3] Biagi L., Caldera S., 2011, The automation of permanent networks monitoring: remarks and case studies, Applied Geomatics, Vol. 3, n. 3, 2011

[4] Biagi L., Caldera S., Visconti M.G., Data Quality and Coordinate Monitoring for a Permanent Network:
Proposals and Experiences, in Proceedings of ION GNSS 2007, September 2007, pp. 687-698

[5] Boucher C., Altamimi Z., Memo, Specifications for reference frame fixing in the analysis of a EUREF GPS campaign, http://lareg.ensg.ign.fr/EUREF/, 2008

[6] Brown N., Keenan R., Richter B., Troyer L., Advances in Ambiguity Resolution for RTK

[7] Caldera, S., GNSS permanent networks monitoring: problems and solution, $\mathrm{PhD}$ Thesis, 2010, on line on geomatica.como.polimi.it

[8] http://igscb.jpl.nasa.gov/

[9] Kouba J. , A guide to using International GPS Service (IGS) products, ftp://igscb.jpl.nasa.gov/igscb/resource/pubs/GuidetoUsi ngIGSProducts.pdf, 2003

[10]Landau H., Vollath U., Chen X., Virtual Reference Station Systems, Journal of Global Positioning Systems Vol. 1, No. 2: 137-143, 2002

[11]Leica Geosystems, Networked Reference stations: take it to the MAX!, Leica Geosystems White paper, June 2005 .

Volume 5 Issue 7, July 2016 www.ijsr.net 